\title{
The induction of heme oxygenase 1 decreases contractility in human internal thoracic artery and radial artery grafts
}

\author{
Paul Achouh, MD, a Serge Simonet, $\mathrm{PhD},{ }^{\mathrm{b}}$ Cécile Badier-Commander, $\mathrm{PhD},{ }^{\mathrm{b}}$ Catherine Chardigny, $\mathrm{MD}, \mathrm{PhD}$, \\ Christine Vayssettes-Courchay, PhD, ${ }^{\text {b }}$ Rachid Zegdi, MD, PhD, ${ }^{a}$ Ziad Khabbaz, MD, ${ }^{a}$ Jean-Noël Fabiani, MD, PhD, ${ }^{a}$ \\ and Tony J. Verbeuren, $\mathrm{PhD}^{\mathrm{b}}$
}

From the Department of Cardiovascular Surgery, ${ }^{\text {a }}$ European Hospital Georges Pompidou, Paris, France, and the Department of Angiology, ${ }^{\mathrm{b}}$ Servier Research Institute, Suresnes, France.

Received for publication March 29, 2005; revisions received June 19, 2005; accepted for publication July 29, 2005

Address for reprints: Paul Achouh, MD, Department of Cardiothoracic and Vascular Surgery, University of Texas-Houston Medical School, Memorial Hermann Hospital. 6410 Fannin Street, Suite 450, Houston, TX 77030 (E-mail: paulachouh@softhome. net).

J Thorac Cardiovasc Surg 2005;130:1573-80 $0022-5223 / \$ 30.00$

Copyright (C) 2005 by The American Association for Thoracic Surgery

doi:10.1016/j.jtcvs.2005.07.055
Objective: Spasm remains a potential problem encountered during the use of arterial grafts in coronary artery bypass surgery. Heme oxygenase plays a role in the control of arterial vasoreactivity. Heme oxygenase exists in 2 constitutive isoforms (heme oxygenase 2 and 3 ) and an inducible isoform (heme oxygenase 1). The aim of our study was to induce heme oxygenase 1 by using hemin in human internal thoracic and radial arteries and to evaluate the effect of this induction on the contractility of these arterial grafts.

Methods: Segments of human arterial grafts obtained from patients undergoing isolated coronary artery bypass surgery were incubated in organ chambers for 4 hours in the presence of $10^{-4} \mathrm{~mol} / \mathrm{L}$ hemin. Concentration-response curves to norepinephrine were obtained in control and hemin-treated arterial rings. Heme oxygenase 1 expression was evaluated by using enzyme-linked immunosorbent assays and immunohistochemical staining.

Results: The contractility of the arterial rings to norepinephrine was significantly reduced after incubation with hemin. Zinc protoporphyrin (an inhibitor of heme oxygenase) reversed the effect of hemin, whereas the inhibitor of nitric oxide synthase had no effect. The inhibitor of soluble guanylate cyclase blocked the decrease in contractility induced by hemin. Immunohistochemical staining revealed a large expression of heme oxygenase 1 in all vascular layers of hemin-treated internal thoracic artery and radial artery rings. Enzyme-linked immunosorbent assay studies showed a significant increase in heme oxygenase 1 levels in hemin-treated internal thoracic artery and radial artery rings.

Conclusion: Hemin caused in vitro induction of heme oxygenase 1 in human internal thoracic artery and radial artery grafts. This induction resulted in a reduced contractility to norepinephrine, partially through the cyclic guanosine monophosphatedependent pathway. This effect was independent from nitric oxide synthesis.

$\mathrm{S}$ ince the first coronary artery bypass in the 1950s, coronary artery surgery has evolved considerably. The internal thoracic artery (ITA) has become the graft of choice for all patients. Other arterial grafts have been explored, but surgeons were initially confronted with problems of spasm and low permeability rates. These spastic properties were often exacerbated by postoperative high circulating levels of vasoconstrictors (like epinephrine). The radial artery (RA) was first used by Carpentier and colleagues in 1971 but was rapidly abandoned after a high rate of postoperative spasm. Its use became viable 10 years later after the introduction of perioperative antispastic treatment. ${ }^{1}$ The current trend in coronary surgery is total arterial revascularization. However, the vasoactive properties of the arterial grafts have yet to be understood, and the optimal vasodilator agent to be used in patients subjected to arterial coronary bypass is still to be defined. 


$$
\begin{aligned}
& \text { Abbreviations and Acronyms } \\
& \begin{aligned}
\text { ELISA } & =\text { enzyme-linked immunosorbent assay } \\
\text { GMP } & =\text { guanosine monophosphate } \\
\text { HO } & =\text { heme oxygenase } \\
\text { ITA } & =\text { internal thoracic artery } \\
\text { LNA } & =\mathrm{N}_{\mathrm{w}} \text {-nitro-L-arginine } \\
\mathrm{NE} & =\text { norepinephrine } \\
\mathrm{NO} & =\text { nitric oxide } \\
\mathrm{ODQ} & =1 \mathrm{H}-[1,2,4] \text { oxadiazolo[ }[4,3,- \text { a }] \text { quinoxalin-1-one } \\
\mathrm{RA} & =\text { radial artery } \\
\mathrm{ZnPP} & =\text { zinc protoporphyrin }
\end{aligned}
\end{aligned}
$$

Currently, heme oxygenase (HO) is viewed as playing an increasingly important role in the regulation of arterial tone, as well as in cellular protection. HO is a microsomal enzyme that breaks down heme to carbon monoxide, biliverdin, and iron. ${ }^{2}$ Biliverdin is reduced to bilirubin, a potent antioxidant, ${ }^{3}$ and carbon monoxide possesses vasorelaxing properties. $^{4,5}$

HO exists in 3 genetically different isoforms: constitutive HO-2 and HO-3, which predominate in physiologic situations, and inducible HO-1, which is mostly found in oxidative and inflammatory conditions.

In vitro animal studies indicate that carbon monoxide, one of the end products of $\mathrm{HO}$, has an important role in the control of vascular tone. ${ }^{4-6}$ In vivo animal studies and studies on cellular cultures have both succeeded in inducing HO-1 by using oxidative stimuli, hypoxia, or physical stress. $^{6-13}$ Other reports have associated HO-1 with the control of vasoreactivity in animals. ${ }^{14-16}$ No report has ever induced HO-1 in human arterial grafts or studied the effect of HO-1 induction on the contractility of these grafts.

The aim of our study was to induce HO-1 in human ITA and RA grafts using hemin and to evaluate the effect of HO-1 induction on the contractility to norepinephrine (NE) of these human grafts. Immunohistochemical and enzymelinked immunosorbent assay (ELISA) studies were used to document the induction of HO-1.

\section{Materials and Methods}

\section{Sampling of Arterial Segments}

Human ITAs and RAs were obtained intraoperatively from 20 patients undergoing elective isolated coronary artery bypass surgery. Table 1 shows the clinical characteristics of these patients. The study was in accordance with the principles outlined in the Declaration of Helsinki and was approved by the local ethical committee. All patients gave their informed consent. The RA was harvested with its pedicle, including the 2 satellite veins. The ITA was skeletonized with low-intensity electrical cautery. After total heparinization of the patient $(3 \mathrm{mg} / \mathrm{kg})$, a short distal arterial segment was harvested for the study just before the bifurcation for the ITA and at the level of the wrist for the RA. No clamping or intraluminal dilatation was performed on the vessels during their
TABLE 1. Clinical characteristics of the patients

\begin{tabular}{lr}
\hline Total no. of patients & 20 \\
Median age (y) & 56 \\
Sex ratio (men/women) & $13 / 7$ \\
Risk factors (n) & 16 \\
Smoking & 7 \\
Diabetes mellitus & 9 \\
Arterial hypertension & 13 \\
Dyslipidemia & \\
Preoperative treatment (n) & 12 \\
B-Blockers & 5 \\
Calcium-channel blockers & 7 \\
Nitrates & 8 \\
ACE inhibitors & \\
Anesthetic drugs (n) & 20 \\
Propofol & 20 \\
Cisatracurium & 20 \\
Fentanyl & 20 \\
Aprotinin & \\
Type of graft harvested (n) & 17 \\
Internal thoracic artery & 12 \\
Radial artery &
\end{tabular}

$A C E$, Angiotensin-converting enzyme.

manipulation. The arterial segments were then immediately immerged in Dulbecco's modified Eagle's solution (Life Technologies) at $4^{\circ} \mathrm{C}$, away from any light exposure.

The mean time between harvesting and experimentation was 20 hours. For experimentation, the blood vessels were cleared of the surrounding adipose tissue under magnification and cut into 3-mmlong rings. The arterial rings were studied in organ baths. Care was taken not to traumatize the endothelium. The number of rings taken from each blood vessel varied from 4 to 10 . Only arterial rings with functional endothelium were retained for this protocol.

\section{Organ Bath Technique}

Arterial rings were mounted on 2 stainless-steel hooks in a 20-mL water-jacketed glass organ bath filled with physiologic Krebs solution maintained at $37^{\circ} \mathrm{C}$. The organ bath experimentation technique has been described by Chardigny and colleagues. ${ }^{17}$ The arterial rings were progressively stretched to the optimal point of their length-tension relationship to study the isometric tension response of the vessels independently of their varying diameter. On the basis of the work of Chardigny and colleagues, the respective resting tensions were $5 \mathrm{~g}$ for the ITA rings and $9 \mathrm{~g}$ for the RA rings.

\section{Vasoreactivity Experimentation Protocol}

First, the contractility of the arterial rings was evaluated in the presence of $10^{-2} \mathrm{mmol} / \mathrm{L} \mathrm{KCl}$. The arterial rings were rinsed afterward to their basal tension. Second, the functionality of the endothelium was verified by means of the endothelium-dependent relaxing effect of $10^{-6} \mathrm{~mol} / \mathrm{L}$ acetylcholine and $10^{-6} \mathrm{~mol} / \mathrm{L}$ calcium ionophore. Third, a cumulative concentration-response curve to $\mathrm{NE}\left(10^{-9} \mathrm{~mol} / \mathrm{L}\right.$ to $\left.10^{-6} \mathrm{~mol} / \mathrm{L}\right)$ was realized in $0.5 \log$-unit steps. Fourth, after rinsing and stabilization, 4 to 5 arterial rings per 
patient were incubated for 4 hours in the presence of $10^{-4} \mathrm{~mol} / \mathrm{L}$ hemin. One to 2 control rings per patient were incubated under the same conditions without hemin. Selective inhibitors of nitric oxide (NO) synthase ( $\mathrm{N}_{\mathrm{w}}$-nitro-L-arginine [LNA] at $\left.10^{-4} \mathrm{~mol} / \mathrm{L}\right)$, soluble guanylate cyclase $(1 \mathrm{H}-[1,2,4]$ oxadiazolo[4,3,-a]quinoxalin-1one [ODQ] at $10^{-5} \mathrm{~mol} / \mathrm{L}$ ), and $\mathrm{HO}$ (zinc protoporphyrin [ZnPP] at $10^{-5} \mathrm{~mol} / \mathrm{L}$ ) were added separately to 3 hemin-treated rings during the last 30 minutes of incubation. The incubations and manipulations were performed in aluminum foil-wrapped organ chambers in a dark room to avoid any induction of HO-1 by light ${ }^{18}$ and because the ZnPP was light sensitive. Finally, after incubation, another concentration-response curve was obtained in the presence of increasing concentrations of NE $\left(10^{-9} \mathrm{~mol} / \mathrm{L}\right.$ to $\left.10^{-6} \mathrm{~mol} / \mathrm{L}\right)$. The concentration-dependent contraction of each arterial ring after the incubation phase was compared with the maximal contraction obtained before the incubation. Each arterial ring before the incubation was therefore used as its own control.

At the end of each experiment, one arterial ring from the hemin-treated group and one arterial ring from the control group were embedded in OCT (Tissus-Tek, Sakura Finetek) and conserved at $-80^{\circ} \mathrm{C}$ for immunohistochemical staining. The rest of the rings (one arterial ring from each group: hemin-treated, LNAtreated, ODQ-treated, and control groups) were immediately frozen at $-80^{\circ} \mathrm{C}$ for later ELISA studies. For each patient, one unmanipulated arterial ring (basal group) was stored in Dulbecco's modified Eagle's medium at $4^{\circ} \mathrm{C}$ during the whole length of isolated organ experimentation.

\section{Immunohistochemical Studies of HO-1 and HO-2}

Immunohistochemical studies were performed with rabbit polyclonal antibodies against HO-1 (H105) and HO-2 (H73; StressGen Biotechnologies). Seven-micrometer transverse serial sections of OCT-embedded arterial rings were fixed for 10 minutes with acetone. Slides were hydrated in phosphate-buffered saline, $\mathrm{pH} 7.4$ (Sigma). Endogenous peroxidases were inactivated with $3 \% \mathrm{H}_{2} \mathrm{O}_{2} /$ $\mathrm{H}_{2} \mathrm{O}$ for 20 minutes at room temperature (LSAB kit, DAKO Cytomation). Nonspecific protein-binding sites were saturated for 60 minutes at room temperature with casein solution (Protein Block Serum-Free, DAKO). Primary polyclonal antibodies against HO-1 (1/25:8 $\mu \mathrm{g} / \mathrm{mL})$ and HO-2 (1/50: $4 \mu \mathrm{g} / \mathrm{mL})$ were diluted in $50 \mathrm{mmol} / \mathrm{L}$ Tris-0,1\% Tween (Antibody Diluent, DAKO) and incubated for 90 minutes at room temperature. Thereafter, slides were rinsed with phosphate-buffered saline-Tween and labeled with the Labeled Streptavidin Biotin kit (DAKO). Slides were revealed with diaminobenzidine as substrate and counterstained with Mayer's hematoxylin. Negative controls were obtained on each slide by using a nonspecific isotypical antibody (rabbit IgG antibody) at the same concentration as the primary antibody.

\section{Quantification of HO-1 With ELISA}

A quantitative detection of HO-1 was done with a human HO-1 ELISA kit (StressGen Biotechnologies). Each frozen arterial ring was extracted with a TisssueLyser (Retsch), $2 \times 2$ minutes at 30 $\mathrm{Hz}$, in $300 \mu \mathrm{L}$ of cold extraction buffer (HO-1 ELISA kit) supplemented with complete protease inhibitors (Complete Mini, Roche Diagnostics). Homogenates were incubated for 1 hour at $4^{\circ} \mathrm{C}$ and then centrifuged $\left(1000 \mathrm{~g}\right.$ for 10 minutes at $\left.4^{\circ} \mathrm{C}\right)$, and supernatants were then stored at $-80^{\circ} \mathrm{C}$. $\mathrm{HO}-1$ protein levels were quantified by means of ELISA, as described by the manufacturer. Soluble proteins were quantified by using the Lowry method (Protein Assay, BioRad). Results of HO-1 levels were expressed as nanograms per milligram of soluble proteins.

\section{Drugs}

The different drugs were prepared before each experimentation. NE, acetylcholine, calcium ionophore, LNA, ODQ, and hemin (bovine hemin chloride) were bought from Sigma, France. Hemin and ZnPP were prepared as described by Shibahara and coworkers. ${ }^{19}$ Photosensitive ZnPP was prepared and manipulated in lightproof containers.

\section{Data and Statistical Analysis}

Tension generated by the blood vessels was digitized by using a computer with IOX software (EMKA Technologies). The results were expressed as a percentage of maximal initial contraction induced by NE. The contractility of the arterial rings after treatment with hemin was compared with the contractility of the control rings and with that of the hemin plus inhibitor-treated rings.

In each experiment the hemin-treated rings and the control rings were harvested from the same patient. For all the studied parameters, $\mathrm{n}$ represented the number of patients. Results were expressed as means \pm standard error of the mean. Statistical analysis was performed with the Student $t$ test for paired values or 2-way analysis of variance, followed by a Bonferroni test for evaluating the effect of treatments. ELISA results were compared with the Student $t$ test.

\section{Results}

\section{Organ Chamber Studies}

NE $\left(10^{-9}\right.$ to $\left.10^{-6} \mathrm{~mol} / \mathrm{L}\right)$ caused concentration-dependent contractions of ITA and RA rings (Figures 1 and 2); at $10^{-6}$ $\mathrm{mol} / \mathrm{L}$, these contractions averaged $3.2 \pm 0.5 \mathrm{~g}$ and $5.3 \pm$ $1.4 \mathrm{~g}$, respectively. The incubation of both ITA and RA segments with the HO-1-inducing substance hemin $\left(10^{-4}\right.$ $\mathrm{mol} / \mathrm{L}$ ) resulted in a significant reduction of the concentrationdependent contractions to NE. This reduction in contractility was completely reversed by the $\mathrm{HO}$ inhibitor $\mathrm{ZnPP}$ $\left(10^{-5} \mathrm{~mol} / \mathrm{L}\right)$ in both ITA and RA segments (Figures 1, A, and 2, $A$, respectively). Also, the guanylate cyclase inhibitor ODQ $\left(10^{-5} \mathrm{~mol} / \mathrm{L}\right)$ significantly reversed the hemin-induced reduction in contractility in both ITA and RA segments (Figure 1, B, and 2, B, respectively). The NO synthase inhibitor LNA $\left(10^{-4} \mathrm{~mol} / \mathrm{L}\right)$ did not significantly modify the effect of hemin on the contractions of the ITA $(75 \% \pm 18 \%$ for LNA vs $73 \% \pm 12 \%$ for control, $\mathrm{n}=3)$ and $\mathrm{RA}(69 \%$ $\pm 9 \%$ for LNA vs $64 \% \pm 1 \%$ for control, $n=3$ ) rings.

\section{Immunohistochemical Identification of HO-1 and HO-2}

In human ITAs and RAs, HO-1 was detected on all layers of rings treated with hemin (Figure 3). HO-1 was localized on 
A

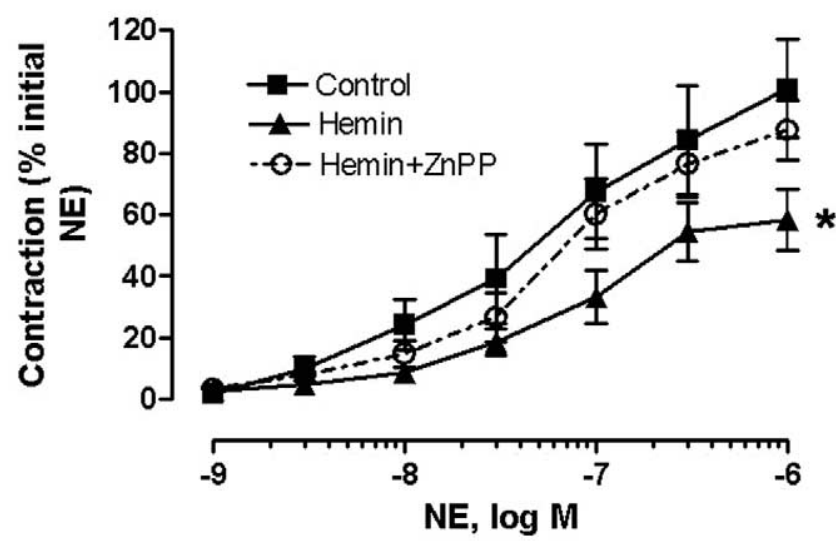

B

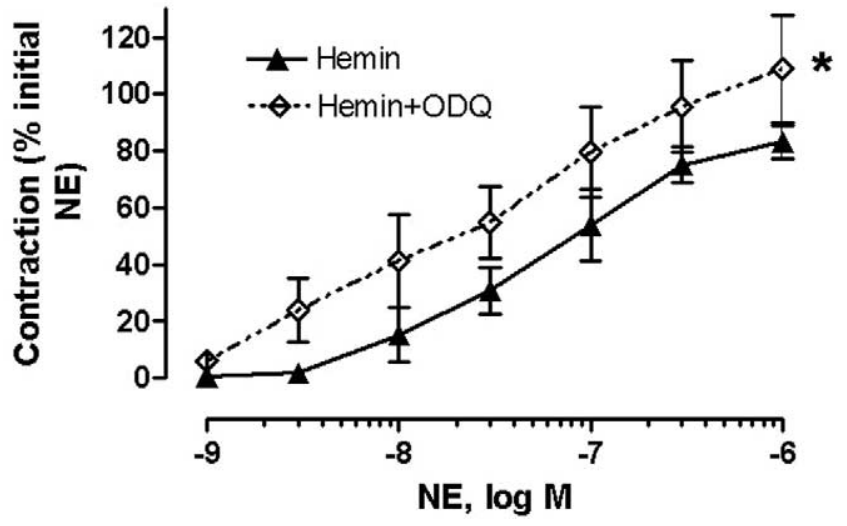

Figure 1. A, Effect of hemin on the concentration-dependent contractions to norepinephrine (NE) in the human internal thoracic artery $(n=7)$. Contractility is expressed as a percentage of initial maximal contraction force $(3.2 \pm 0.5 \mathrm{~g})$ induced by NE. The treatment with hemin significantly decreased the contractile effect of NE $(* P<.05)$; the contractility was restored by zinc protoporphyrin (ZnPP) to a similar level than that of the control rings. $B$, Effect of $1 \mathrm{H}-[1,2,4]$ oxadiazolo[4,3,-a]quinoxalin-1-one (ODQ) on the concentration-dependent contractions to NE in hemin-treated human internal thoracic artery rings $(n=5-6)$. Contractility is expressed as a percentage of maximal contraction $(2.2 \pm 0.4 \mathrm{~g})$ induced by NE. The addition of ODO to hemintreated rings significantly increased the contractility induced by NE $\left({ }^{*} P<.05\right)$.

endothelial cells, smooth muscle cells, fibroblasts, and also on endothelial cells of the microvasculature. HO-1 was mildly detected on cells of control ITA and RA rings. The constitutive HO-2 protein was observed on all arterial cells of control and hemin-treated rings in both the ITA and RA groups (Figure 4).
A

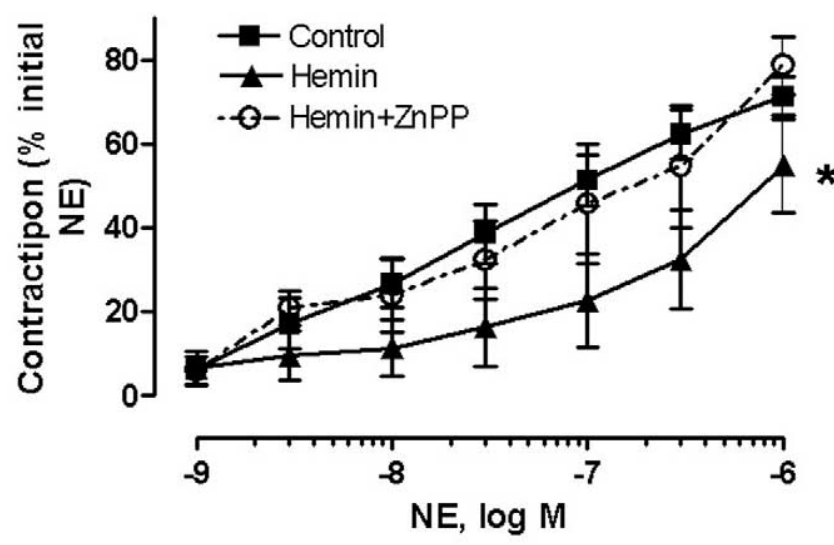

B

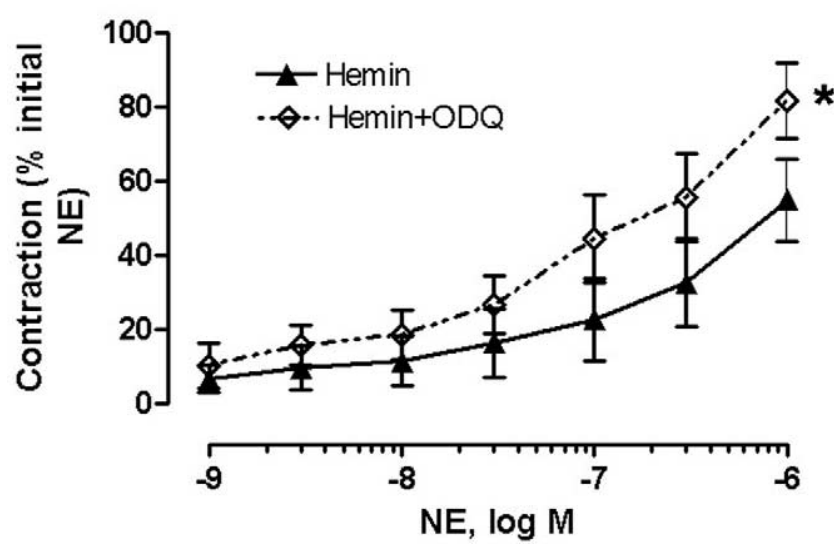

Figure 2. A, Effect of hemin on the concentration-dependent contractions to norepinephrine (NE) in the human radial artery ( $\mathrm{n}=$ 5). Contractility is expressed as a percentage of initial maximal contraction force $(5.3 \pm 1.4 \mathrm{~g})$ induced by NE. Treatment with hemin significantly decreased the contractile effect of $\mathrm{NE}\left({ }^{*} P<\right.$ .05). The inhibition was restored by zinc protoporphyrin (ZnPP) at a similar level than that of the control rings. $B$, Effect of the addition of $1 \mathrm{H}-[1,2,4]$ oxadiazolo[4,3,-a]quinoxalin-1-one (ODQ) on the concentration-dependent contractions to $\mathrm{NE}$ in hemin-treated human RA rings $(\mathbf{n}=5)$. Contractility is expressed as a percentage of maximal contraction $(5.5 \pm 1.5 \mathrm{~g})$ induced by NE. The addition of ODQ to hemin-treated rings significantly increased the contractility induced by NE $\left({ }^{*} P<.05,2\right.$-way analysis of variance).

Detection of HO-1 by Means of ELISA

In ITA rings the levels of soluble proteins were identical in the different groups studied: $1.10 \pm 0.10,1.06 \pm 0.06$, and $1.01 \pm 0.06 \mathrm{mg} / \mathrm{mL}$, respectively, for the hemin-treated, hemin plus ZnPP-treated, and control groups. Figure 5, A, 


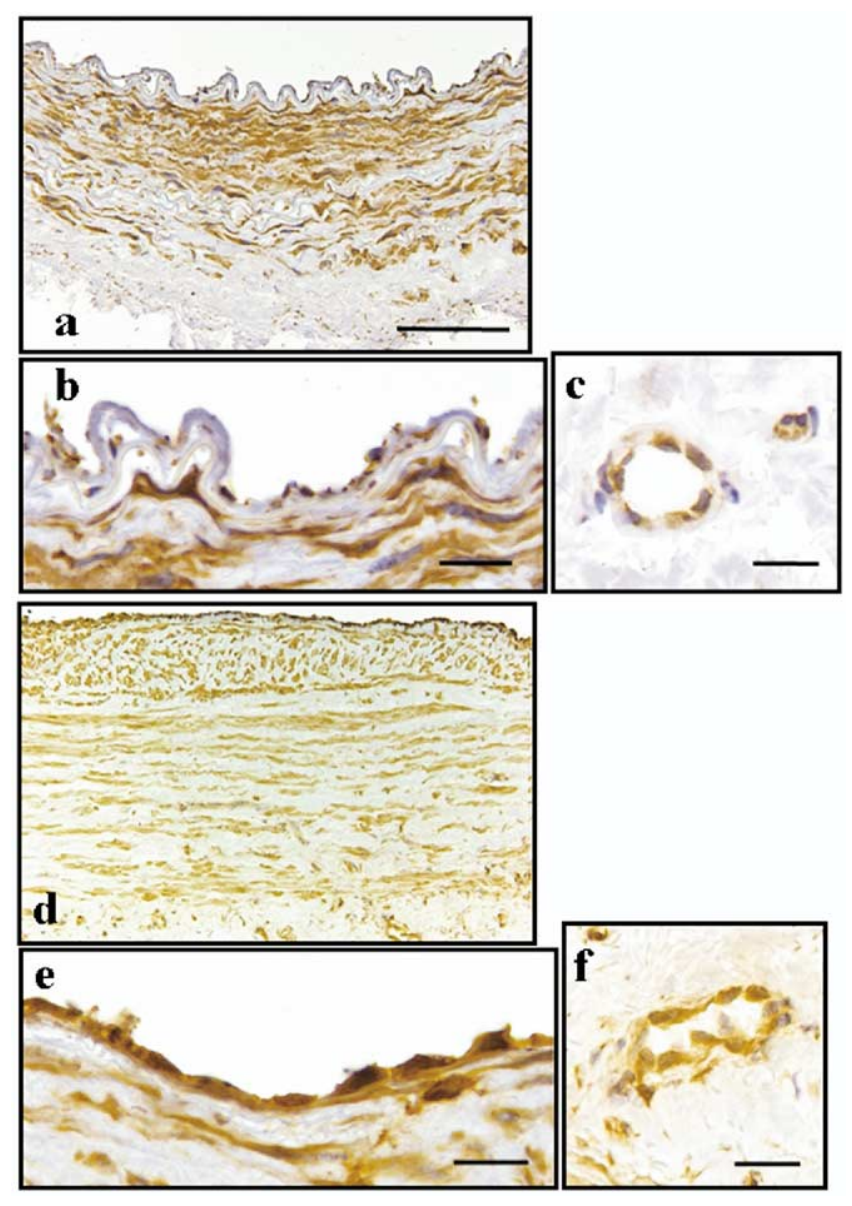

Figure 3. A, Immunohistochemical detection of heme oxygenase 1 in hemin-treated internal thoracic artery $(n=5)$. Heme oxygenase 1 was detected in all layers of the artery: smooth muscle cells of the media (a), endothelium (b), and adventitial microvessels (c). B, Immunohistochemical detection of heme oxygenase 1 in hemin-treated radial artery $(n=5)$. Heme oxygenase 1 was detected in all layers of the artery: smooth muscle cells of the media (d), endothelium (e), and adventitial microvessels ( $f$ ). Bar $=$ $100 \mu \mathrm{m}$ in $a$ and $200 \mu \mathrm{m}$ in $d$ and $20 \mu \mathrm{m}$ in $b, c, e$, and $f$.

represents HO-1 levels as measured by means of ELISA in the hemin-treated and hemin plus ZnPP-treated ITA groups compared with those in the control group.

In RA rings, similar to ITA rings, the levels of soluble proteins were identical in the different groups studied: $1.80 \pm$ $0.23,1.73 \pm 0.29$, and $1.57 \pm 0.14 \mathrm{mg} / \mathrm{mL}$, respectively, for the hemin-treated, hemin plus ZnPP-treated, and control groups. Figure 5, B, represents $\mathrm{HO}-1$ levels as measured by means of ELISA in the hemin-treated and hemin plus ZnPPtreated RA groups compared with those in the control group.

ELISA studies done on unmanipulated arterial segments stored at $4{ }^{\circ} \mathrm{C}$ during the time of the experience (basal group) showed a minimal induction of HO-1 in both the ITA and

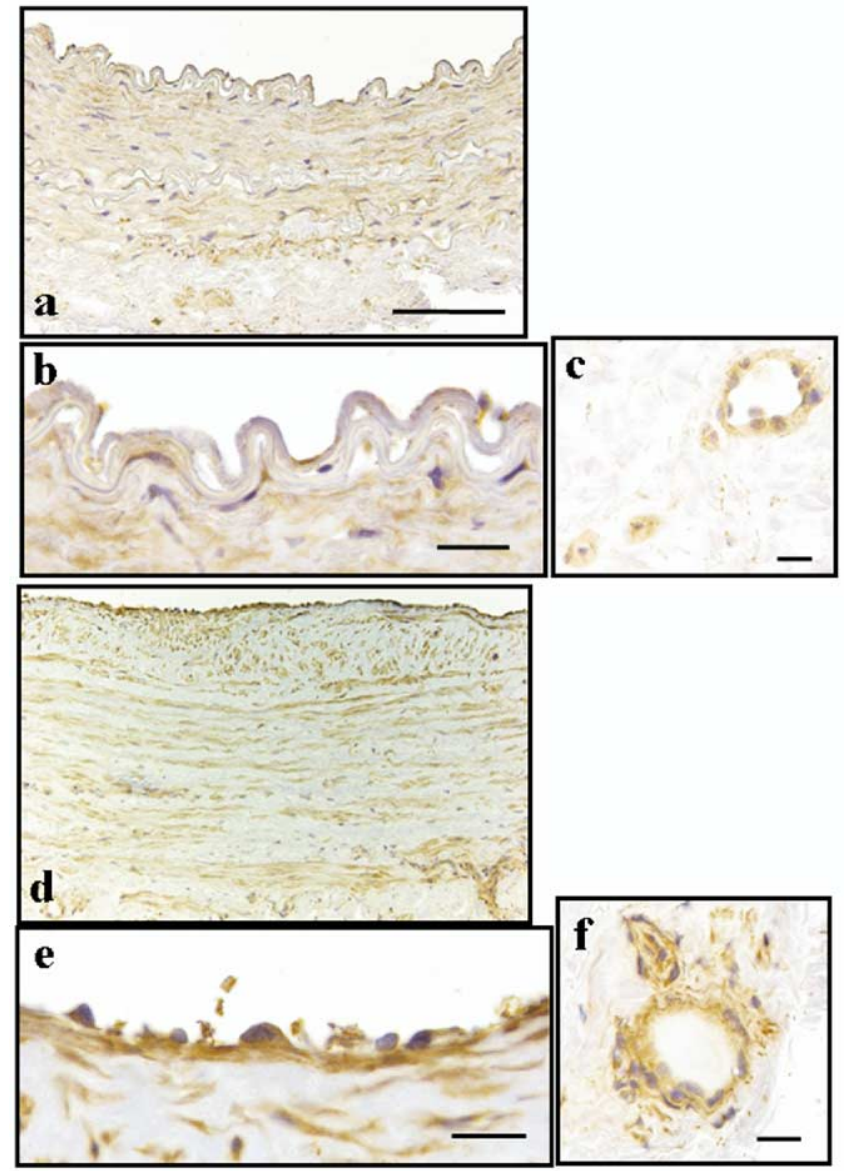

Figure 4. A, Immunohistochemical detection of heme oxygenase 2 in hemin-treated internal thoracic artery $(n=5)$. Heme oxygenase 2 was detected in all layers of the artery: smooth muscle cells of the media (a), endothelium (b), and adventitial microvessels (c). B, Immunohistochemical detection of heme oxygenase 2 in hemin-treated radial artery $(n=5)$. Heme oxygenase 2 was detected in all layers of the artery: smooth muscle cells of the media (a), endothelium (b), and adventitial microvessels (c). $B$ ar $=100$ $\mu \mathrm{m}$ in $a$ and $200 \mu \mathrm{m}$ in $d$ and $20 \mu \mathrm{m}$ in $b, c, e$, and $f$.

RA groups $(3.3 \pm 0.8 \mathrm{ng} / \mathrm{mg}$ soluble proteins and $4.8 \pm 1.9$ $\mathrm{ng} / \mathrm{mg}$ soluble proteins, respectively) compared with that seen in the control group.

The control levels of HO-1 were higher in the RA rings than in the ITA rings $(26.0 \pm 5.0 \mathrm{vs} 10.9 \pm 2.0 \mathrm{ng} / \mathrm{g}$ soluble protein). The relative increase of HO-1 expression by hemin was higher in RA rings than in ITA rings (1.7-fold vs 1.4-fold, respectively).

\section{Discussion}

The major achievement of the present study is the demonstration of HO-1 induction in human arteries and its consequences on arterial contractility. Indeed, the incubation of 

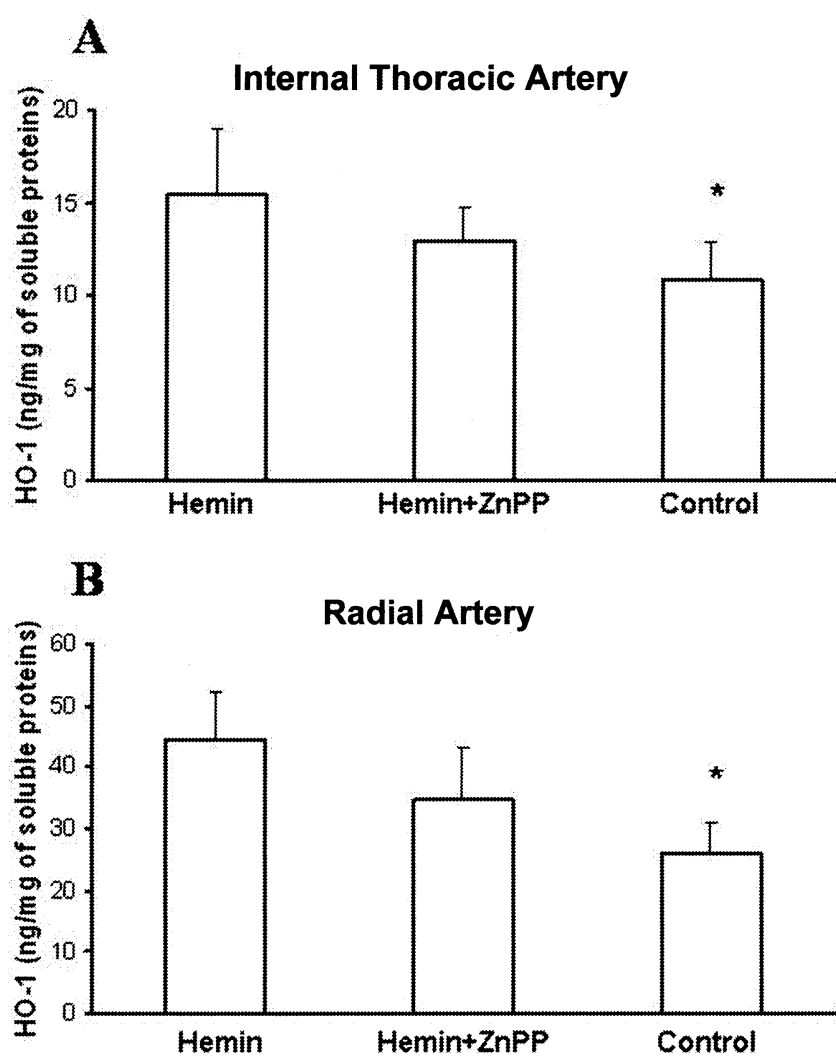

Figure 5. A, Enzyme-linked immunosorbent assay quantification of heme oxygenase $1(\mathrm{HO}-1)$ in hemin-treated human internal thoracic artery rings compared with that in control and hemin plus zinc protoporphyrin $(Z n P P)$-treated rings $(n=6)$. Hemin treatment increased H0-1 production compared with control values $(15.4 \pm 3.6$ vs $10.9 \pm 2.0 \mathrm{ng} / \mathrm{mg}$ soluble proteins, respectively; $\left.{ }^{*} P<.05\right)$. ZnPP did not change the level of HO-1 production compared with hemin treatment $(13.0 \pm 1.8 \mathrm{vs} 15.4 \pm 3.6 \mathrm{ng} / \mathrm{mg}$ soluble proteins). Control, Control arterial rings; Hemin, hemintreated rings; ZnPP, hemin plus ZnPP-treated rings. B, Enzymelinked immunosorbent assay quantification of $\mathrm{HO}-1$ in hemintreated human radial artery rings compared with that in control and $\mathrm{ZnPP}$-treated rings $(\mathrm{n}=5$ ). Hemin treatment increased HO-1 production compared with control values $(44.7 \pm 7.5$ vs $26.0 \pm 5.0$ $\mathrm{ng} / \mathrm{mg}$ soluble proteins, respectively; $\left.{ }^{*} P<.05\right)$. ZnPP did not change the level of $\mathrm{HO}-1$ production compared with hemin treatment (34.9 \pm 8.3 vs $44.7 \pm 7.5 \mathrm{ng} / \mathrm{mg}$ soluble proteins). Control, Control arterial rings; Hemin, hemin-treated rings; ZnPP, hemin plus ZnPP-treated rings.

human ITA and RA rings for 4 hours at $37^{\circ} \mathrm{C}$ with $10^{-4}$ $\mathrm{mol} / \mathrm{L}$ hemin induced the synthesis of HO-1, as proved by immunohistochemical and ELISA studies. On immunohistochemical staining, constitutive HO-2, which normally predominates in the cardiovascular system, ${ }^{2}$ was found on all the layers of both the hemin-treated and the control arterial rings. The induction of HO-1 by hemin was confirmed on the different layers of the hemin-treated rings.
The mild expression of HO-1 observed in the control rings might have been related to the conditions of experimentation, the manipulation of the arterial segments during their harvesting, their conservation conditions, and their stretching into their resting tension, all of which constitute elements of physical stress or hypoxia that have been shown to induce HO-1 in animals. ${ }^{9,20}$ The storage of arterial segments at $4{ }^{\circ} \mathrm{C}$ before manipulation did not induce significant levels of HO-1 in ITA or RA rings as has been shown by means of ELISA studies done on the basal groups (unmanipulated control rings stored at $4{ }^{\circ} \mathrm{C}$ during the experimentation period).

On the other hand, most of the study patients were taking multiple vasoactive medications, such as nitrates, $\beta$ blockers, calcium-channel blockers, and angiotensin-converting enzyme inhibitors. This might have been responsible for an induction of HO-1 in some of these groups or in a decrease in initial contractility in others. This would not have influenced our results but only attenuated the statistical significance of our results because all arterial segments in one experiment were taken from the same patient.

The basal level and the increase in the production of HO-1 were higher in RA rings compared with that seen in ITA rings. Other reports have shown that the production of $\mathrm{NO}$ is superior in ITAs compared with that seen in RAs. ${ }^{21}$ These differences in the expression of HO-1 might be related to a more predominant role of $\mathrm{HO}$ in the control of RA tone compared with that seen in the ITA.

Our results constitute the first report illustrating the in vitro induction of HO-1 by hemin in human isolated arteries. Yoshida and associates ${ }^{11}$ succeeded in inducing $\mathrm{HO}$ mRNA production in a culture of human macrophages treated with $10^{-5} \mathrm{~mol} / \mathrm{L}$ hemin for 3 hours. Panchenko and colleagues $^{12}$ induced HO-1 in human dermal fibroblast culture using hypoxia. Terry and coworkers ${ }^{13}$ stimulated the production of HO-1 using tumor necrosis factor and interleukin $1 \alpha$ in human endothelial cell culture.

Other studies have shown that hemin induces HO-1 synthesis in animals. Clark and associates ${ }^{22}$ found that a 4-hour incubation of bovine vascular smooth muscle cells in the presence of $10^{-4} \mathrm{~mol} / \mathrm{L}$ hemin provided the maximal induction of HO-1 with the least cellular toxicity. Two years earlier, Vesely and colleagues ${ }^{23}$ had shown that the optimal concentration of hemin for the induction of HO-1 in a rat myoblast cell culture was less than $2 \times 10^{-6} \mathrm{~mol} / \mathrm{L}$. We chose the protocol of incubation in our study on the basis of these reports. Other authors ${ }^{20,24}$ were able to induce HO-1 in cultured rat muscular cells by using different stimuli, such as heavy metals (cadmium and cobalt), hemin, hypoxia, and hyperthermia.

In our study the 4-hour in vitro incubation of human ITA and $\mathrm{RA}$ rings in the presence of $10^{-4} \mathrm{~mol} / \mathrm{L}$ hemin significantly reduced the contractility to NE. This decrease in 
contractility coincided with a significant increase in the production of HO-1 confirmed by means of ELISA. This is the first report showing that HO-1 can reduce contractility in isolated human arterial grafts. Furthermore, the decrease in contractility after hemin incubation was completely inhibited by the addition of $10^{-5} \mathrm{~mol} / \mathrm{L} \mathrm{ZnPP}$, which is known to be a selective inhibitor of $\mathrm{HO}$ at this concentration. ${ }^{25,26}$ The addition of LNA, a selective inhibitor of NO synthesis, did not modify the effect of hemin. This suggests that the decrease in contractility was mediated by an increase in $\mathrm{HO}$ activity and was independent of the NO pathway. The addition of ODQ, an inhibitor of soluble guanylate cyclase,${ }^{27}$ significantly reversed the effect of HO-1 induction on contractility. Therefore the vasorelaxing effect related to $\mathrm{HO}$ induction was mainly mediated by the stimulation of soluble guanylate cyclase and the resulting production of cyclic guanosine monophosphate (GMP). These findings are in agreement with the results of several other studies. ${ }^{2,16,24,28}$ Other cyclic GMP-independent pathways might also participate in the reduction of the contractile response to $\mathrm{NE}^{29,30}$

In an experiment comparable with ours, Wang and colleagues ${ }^{5}$ incubated rat-tail arteries in the presence of hemin. They reported a significant reduction in contractility to NE. As in our study, this effect was completely inhibited by ZnPP but not by LNA. Caudill and coworkers ${ }^{16}$ incubated segments of rat aorta in the presence of sodium arsenite, an inducer of HO-1. They reported an increase in the production of HO-1 mRNA, as well as a decrease in the contractility of the arterial segments. This latter effect was also inhibited by the addition of ZnPP. An in vivo animal study ${ }^{6}$ also showed that hemin induces a decrease in blood pressure and in vascular tone through the induction of HO- 1 . The similarity in the in vitro reactivity caused by HO-1 induction between the animal studies and the present human study suggests that if HO-1 was induced in vivo in human subjects, the hemodynamic consequences might resemble those described above in experimental animals. Further future in vivo studies might prove HO-1 induction in human subjects to be beneficial in the control of hypertension or in preventing vasospasm in arterial bypass or other vasospastic diseases.

\section{Conclusion}

This study illustrates the induction of HO-1 in human ITA and RA grafts after in vitro incubation with hemin. The induction of HO-1 attenuated the contractility in response to NE. The decrease in contractility was independent of the NO pathway and at least partially mediated by the stimulation of the cyclic GMP pathway. Further experiments are needed to identify the cyclic GMP-independent pathways activated by $\mathrm{HO}$.

Complementary studies need to be undertaken to accelerate the induction of HO-1 by using more physiologic stimuli than hemin and to study the effect of HO-1 induction on endogenous vasoactive factors that are found in high concentrations after cardiopulmonary bypass. A greater expression of HO-1, induction of HO-1, or both in an arterial graft before its use might help prevent postoperative spasm or ameliorate the long-term permeability of these arterial grafts used in coronary artery surgery.

We thank the Department of Angiology at Servier Research Institute for its valuable technical assistance and the Department of Cardiovascular Surgery at the European Hospital Georges Pompidou for its contribution to the completion of this study. We also thank Kirk Soodhalter for his editorial assistance.

\section{References}

1. Acar C, Jebara VA, Portoghese M, Beyssen B, Pagny JY, Grare P, et al. Revival of the radial artery for coronary artery bypass grafting. Ann Thorac Surg. 1992;54:652-60.

2. Maines MD. The heme oxygenase system: a regulator of second messenger gases. Annu Rev Pharmacol Toxicol. 1997;37:517-54.

3. Stocker P, Yamamoto Y, McDonach AF, Glazer AN, Ames BN. Bilirubin is an antioxidant of possible physiological importance. Science. 1987;235:1043-7.

4. Vedernikov YP, Graser T, Vanin AF. Similar endothelium-independent arterial relaxation by carbon monoxide and nitric oxide. Biomed Biochim Acta. 1989;48:601-3.

5. Wang R, Wang $\mathrm{Z}$, Wu L. Carbon monoxide-induced vasorelaxation and the underlying mechanisms. Br J Pharmacol. 1997;121:927-34.

6. Ndisang JF, Zhao W, Wang R. Selective regulation of blood pressure by heme oxygenase- 1 in hypertension. Hypertension. 2002;40:315-21.

7. Christou H, Morita T, Hsieh C-M, Koike H, Arkonac B, Perrella MA, et al. Prevention of hypoxia-induced pulmonary hypertension by enhancement of endogenous heme oxygenase-1 in the rat. Circ Res. 2000;86:1224-9.

8. Maulik N, Sharma HS, Das DK. Induction of the haem oxygenase gene expression during the reperfusion of ischemic rat myocardium. J Mol Cell Cardiol. 1996;28:1261-70.

9. Wagner CT, Durante W, Christodoulides N, Hellums JD, Schafer AI. Hemodynamic forces induce the expression of heme oxygenase in cultured vascular smooth muscle cells. J Clin Invest. 1997;100: 589-96.

10. Yet SF, Pellacani A, Patterson C, Tan L, Folta SC, Foster L, et al. Induction of heme oxygenase-1 expression in vascular smooth muscle cells. J Biol Chem. 1997;272:4295-301.

11. Yoshida T, Biro P, Müller RM, Shibahara S. Human heme oxygenase cDNA and induction of its mRNA by hemin. Eur J Biochem. 1988; 171:457-61.

12. Panchenko MV, Farber HW, Korn JH. Induction of heme oxygenase-1 by hypoxia and free radicals in human dermal fibroblasts. Am J Physiol Cell Physiol. 2000;278:C92-101.

13. Terry CM, Clikeman JA, Hoidal JR, Callahan KS. Effect of tumor necrosis factor-alpha and interleukin-1 on heme oxygenase-1 expression in human endothelial cells. Am J Physiol Heart Circ Physiol. 1998;274:H883-91.

14. Johnson RA, Lavesa M, Askari B, Abraham NG. A heme oxygenase product, presumably carbon monoxide, mediates a vasodepresssor function in rats. Hypertension. 1995;25:166-9.

15. Jernigan NL, O'Donaughy TL, Walker BR. Correlation of HO-1 expression with onset and reversal of hypoxia-induced vasoconstrictor hyporeactivity. Am J Physiol Heart Circ Physiol. 2001;281:H298-307.

16. Caudill TK, Resta TC, Kanagy NL, Walker BR. Role of endothelial carbon monoxide in attenuated vasoreactivity following chronic hypoxia. Am J Physiol. 1998;275:R1025-30.

17. Chardigny C, Jebara VA, Acar C, Descombes J-J, Verbeuren TJ, Carpentier A, et al. Vasoreactivity of the radial artery: comparison 
with the internal mammary and gastroepiploic arteries with implications for coronary artery surgery. Circulation. 1993;88:115-27.

18. Ossola JO, Tomaro ML. Heme oxygenase induction by UVA radiation. A response to oxidative stress in rat liver. Int J Biochem Cell Biol. 1998;30:285-92.

19. Shibahara S, Yoshida T, Kikuchi G. Induction of heme oxygenase by hemin in cultured pig alveolar macrophages. Arch Biochem Biophys. 1978;188:243-50.

20. Eyssen-Hernandez R, Ladoux A, Frelin C. Differential regulation of cardiac heme oxygenase-1 and vascular endothelial growth factor mRNA expressions by hemin, heavy metals, heat shock and anoxia. FEBS Lett. 1996;382:229-33.

21. Gaudino M, Toesca A, Maggiano N, Pragliola C, Possati G. Localization of nitric oxide synthase type III in the internal thoracic and radial arteries and the great saphenous vein: a comparative immunohistochemical study. J Thorac Cardiovasc Surg. 2003;125:1510-5.

22. Clark JE, Foresti R, Green CJ, Motterlini R. Dynamics of haem oxygenase-1 expression and bilirubin production in cellular protection against oxidative stress. Biochem J. 2000;348:615-9.

23. Vesely MJJ, Exon DJ, Clark JE, Foresti R, Green CJ, Motterlini R. Heme oxygenase-1 induction in skeletal muscle cells: hemin and sodium nitroprusside are regulators in vitro. Am J Physiol Cell Physiol. 1998;275:C1087-94.
24. Christodoulides N, Durante W, Kroll MH, Schafer AI. Vascular smooth muscle cell heme oxygenases generate guanylyl cyclase-stimulatory carbon monoxide. Circulation. 1995;91:2306-9.

25. Appleton SD, Chretien ML, McLaughlin BE, Hendrik JV, Stevenson DK, Brien JF, et al. Selective inhibition of heme oxygenase, without inhibition of nitric oxide synthase or soluble guanylyl cyclase, by metalloporphyrins at low concentrations. Drug Metab Dispos. 1999; 27:1214-9.

26. Maines MD. Zinc-protoporphyrin is a selective inhibitor of heme oxygenase activity in the neonatal rat. Biochim Biophys Acta. 1981; 673:339-50

27. Hussain AS, Marks GS, Brien JF, Nakatsu K. The soluble guanylyl cyclase inhibitor $1 \mathrm{H}-[1,2,4]$ oxadiazolo[4,3-a]quinoxalin-1-one (ODQ) inhibits relaxation by carbon monoxide, nitric oxide, and glyceryl trinitrate. Can J Pharmacol. 1997;75:1034-7.

28. Gonzales RJ, Walker BR. Role of $\mathrm{CO}$ in attenuated vasoconstrictor reactivity of mesenteric resistance after chronic hypoxia. Am J Physiol Heart Circ Physiol. 2002;282:H30-7.

29. Wang R, Wu L. The chemical modification of KCa channels by carbon monoxide in vascular smooth muscle cells. J Biol Chem. 1997;272: 8222-6.

30. Coceani F, Kelsey L, Seidlitz E. Carbon monoxide-induced relaxation of the ductus ateriosus in the lamb: evidence against the prime role of guanylyl cyclase. Br J Pharmacol. 1996;118:1689-96.

Access to The Journal of Thoracic and Cardiovascular Surgery Online is reserved for print subscribers!

Full-text access to The Journal of Thoracic and Cardiovascular Surgery Online is available for all print subscribers. To activate your individual online subscription, please visit The Journal of Thoracic and Cardiovascular Surgery Online, point your browser to http://www.mosby.com/jtcvs, follow the prompts to activate your online access, and follow the instructions. To activate your account, you will need your subscriber account number, which you can find on your mailing label (note: the number of digits in your subscriber account number varies from 6 to 10). See the example below in which the subscriber account number has been circled:

\section{Sample mailing label}

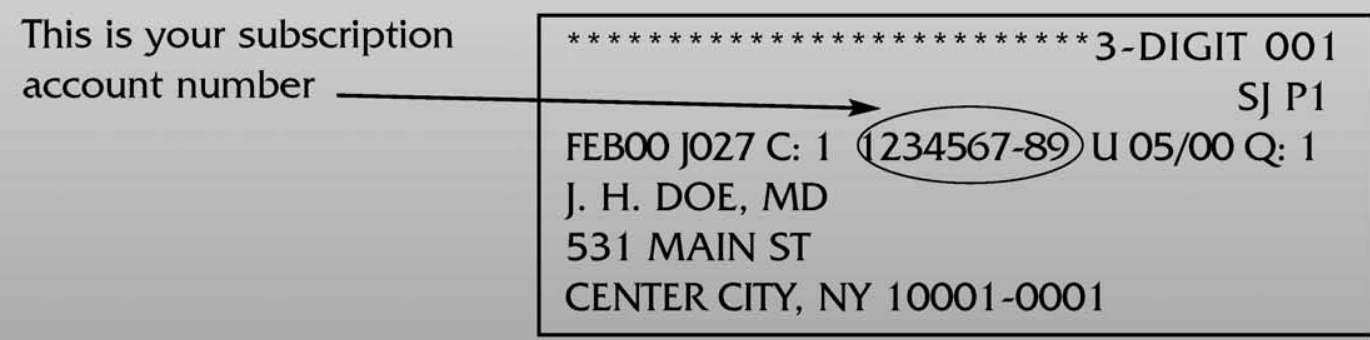

Personal subscriptions to The Journal of Thoracic and Cardiovascular Surgery Online are for individual use only and may not be transferred. Use of The Journal of Thoracic and Cardiovascular Surgery Online is subject to agreement to the terms and conditions as indicated online. 